\title{
Decreased proliferation of human melanoma cell lines caused by antisense RNA against translation factor elF-4AI
}

\author{
J Eberle*,', LF Fecker', J-U Bittner', CE Orfanos' and CC Geilen' \\ 'Department of Dermatology, University Medical Center Benjamin Franklin, The Free University of Berlin, Fabeckstrasse 60-62, 14195 Berlin, Germany
}

\begin{abstract}
Control of translation initiation was recognised as a critical checkpoint for cell proliferation and tumorigenesis. In human melanoma cells, we have previously reported consistent overexpression of translation initiation factor elF-4AI. Here, we investigated by transfection of antisense constructs its significance for the control of melanoma cell growth. The tetracyclineinducible expression system was established in melanoma cells, and three fragments of the $5^{\prime}$-, central-, and $3^{\prime}$-portion of the elF-4AI cDNA were subcloned in antisense and in sense orientation after a tetracycline inducible promoter. Significant proliferation decrease was obtained after transient transfection and induction of antisense RNA directed against the $5^{\prime}$ - and the central portion (up to 10\%), whereas, no effects were seen after induction of the $3^{\prime}$-fragment and the sense controls. Cell clones stably transfected with the central antisense fragment revealed after doxycycline induction reduced expression of endogeneous elF-4AI mRNA correlated with decreased proliferation rates (up to 6\%). These data demonstrate the applicability of antisense strategies against translation factors in melanoma cells. Translation initiation factor elF-4AI contributes to the control of melanoma cell proliferation and may be taken into consideration when scheduling new therapeutic approaches targeting the translational control.

British Journal of Cancer (2002) 86, 1957 - 1962. doi:I0.1038/sj.bjc.660035I www.bjcancer.com
\end{abstract}

(c) 2002 Cancer Research UK

Keywords: melanoma; translation control; antisense; proliferation; apoptosis

Control of protein synthesis is known as a cellular mechanism important for saving energy resources and for rapidly responding to changing growth requirements. In recent years more and more data are emerging on the involvement of this process in cell growth and in tumorigenesis. It is mainly the initiation of translation, which turned out to be a checkpoint for cell proliferation.

In eucaryotes, initiation of translation, which brings mRNA and ribosomal subunits together, is triggered by a number of initiation factors (eIF). This process may be subdivided into five steps corresponding to five groups of translation initiation factors (Rhoads, 1993). The starting point of the initiation process may be seen in the binding of eIF-2 to the initiator-tRNA and to GTP in a ternary complex, which subsequently binds the $40 \mathrm{~S}$ small ribosomal subunit resulting in the $43 \mathrm{~S}$ pre-initiation complex. In parallel, eIF-4E binds to the mRNA cap structure as well as to eIF-4G, which itself is a large polypeptide supplying binding sites for eIF-4A and eIF-3. This complex enables transient melting of the mRNA secondary structure to then allow the ribosomal subunit to enter and scan the mRNA in $3^{\prime}$ direction for the initiation codon. For RNA melting, the helicase activity described for eIF-4A is essential (Ray et al, 1985).

In current therapeutic strategies against cancer less interest has been focussed on protein synthesis mechanisms. However, an increasing body of data is emerging about the involvement of translational processes and factors in control of cell proliferation, also indicating that protein synthesis can be an additional target for anticancer strategies (Caraglia et al, 2000). In order to characterise malignant melanoma cells, we had isolated and identified a

*Correspondence: J Eberle; E-mail: eberle@ukbf.fu-berlin.de Received 24 July 200 I; revised I4 March 2002; accepted 9 April 2002 number of genes specifically regulated in human melanoma cells as compared to normal human melanocytes (Eberle et al, 1995a,b, 1997, 1999). Within this group of genes, we identified the translation initiation factor eIF-4A1 (Eberle et al, 1997), found consistently upregulated at the mRNA level. As the oncogenic potential of other translation initiation factors (e.g., eIF-4E and eIF-2, had already been described in other cells; Lazaris-Karatzas et al, 1990; Donze et al, 1995), we suggested that eIF-4A1 upregulation may contribute specifically to the malignant phenotype of melanoma. In the present paper, we addressed the question whether we can confer inhibitory effects on melanoma cells by obstructing eIF-4Al gene expression using transient and stable transfection of antisense constructs against eIF-4A1.

\section{MATERIALS AND METHODS}

\section{Cell cultivation and transfection}

Melanoma cell lines were maintained in DMEM (4.5 $\mathrm{g} \mathrm{l}^{-1}$ glucose; Gibco, Paisley, Scotland) supplemented with $10 \%$ foetal calf serum, penicillin and streptomycin (Biochrom, Berlin, Germany). For cell transfection, eight different lipids were tested (Pfx-1-Pfx-8; Invitrogen, Groningen, Netherlands), and for the subsequent experiments, Pfx-2, which showed the best transfection efficiency was consequently used. At a confluence of $50 \%$, cells were washed in serum-free Opti-MEM (Gibco) and were incubated at $37^{\circ} \mathrm{C}$ in the same medium containing $0.5 \% \mathrm{Pfx}-2$ and $1.5 \mu \mathrm{g} \mathrm{ml}^{-1}$ plasmid DNA. After $2 \mathrm{~h}$, cells were washed once and were further incubated with standard growth medium, which contained $2 \mu \mathrm{g} \mathrm{ml}^{-1}$ doxycycline (ICN, Aurora, OH, USA) in case of induction. For stable transfections, selective antibiotics, geneticin (Gibco; $400 \mu \mathrm{g} \mathrm{ml}^{-1}$ ) or hygromycin (Boehringer, Mannheim, Germany; $100 \mu \mathrm{g} \mathrm{ml}^{-1}$ ), 
were added, and selection was carried out until only transfected cells remained. Cell clones were obtained by limited dilution in microtitre plates and were continuously cultured under antibiotic pressure (geneticin and/or hygromycin).

Two tetracycline-inducible cell lines SKM13-Tet-On and BroTet-On were established from the cell lines Bro and SK-Mel-13 (Carey et al, 1976; Lockshin et al, 1985), respectively, by stable transfection of the pTet-On plasmid (Clontech, Palo Alto, CA, USA). The tetracycline-inducible gene expression system had been described by Gossen and Bujard (1992). After stable transfection, individual cell clones were screened for their tetracycline inducibility by transient transfection of the luciferase-encoding plasmid pTRE-Luc (Clontech) followed by a luciferase assay (De Wet et al, 1987; Promega, Madison, WI, USA), $48 \mathrm{~h}$ after transfection. For promoter induction, doxycycline was used instead of tetracycline as recommended by the supplier of the vector system (Clontech). As a standard for the luciferase assay, purified luciferase (Promega; $3.3 \times 10^{10}$ light units per $\mathrm{mg}$ protein) was used. Double stable transfectants were obtained after transfection of Bro-Tet-On with an eIF-4A1 antisense construct in pTRE-1 and co-transfection with the hygromycin resistance plasmid pTK-Hyg (1:20 molar ratio; both plasmids from Clontech).

\section{Construction of antisense and control plasmids}

Of the eIF-4A1 cDNA, which we had cloned earlier (Eberle et al, 1997), three different fragments from the $5^{\prime}$ end, of the central portion and from the $3^{\prime}$ end, respectively, were subcloned by restriction and ligation in antisense and in sense orientation, in one or two copies, behind the tetracycline-inducible CMV promoter present in the plasmid pTRE-1. Plasmid DNA used for cell transfection was purified by an endotoxin-free plasmid purification kit (Birnboim and Doly, 1979; Qiagen, Hilden, Germany).

\section{RNA extraction and Northern blotting}

Cells were harvested at $70 \%$ confluence, after adding fresh growth medium $24 \mathrm{~h}$ before. Total RNA was isolated from trypsinised cells using the RNeasy Mini Kit (MacDonald et al, 1987; Qiagen, Hilden, Germany). For Northern blotting (Thomas, 1980), $10 \mu \mathrm{g}$ of total RNA per lane were separated in formaldehyde/agarose gels (1.2\% agarose). For determination of mRNA length, a $0.24-9.5 \mathrm{~kb}$ RNA ladder (Gibco, Gaithersburg, TN, USA) was used. RNA was transferred by capillary blotting to Gene Screen Plus membranes (NEN Life Science, Cologne, Germany), and hybridisations were carried out at $60^{\circ} \mathrm{C}$ for $16 \mathrm{~h}$. Probes for eIF-4Al and $\beta$-actin derived from a differential screening (Eberle et al, 1995a); the cDNA fragments were radiolabelled by random priming (Gibco) followed by purification with Nuc-trap push columns (Stratagene, La Jolla, CA, USA). Membranes were washed under stringent conditions $\left(45 \mathrm{~min}\right.$ at $65^{\circ} \mathrm{C}$ in $2 \times$ sodium citrate buffer, SSC) and were then exposed to an imaging plate for quantification of radioactivity by a BAS-1500 Phosphoimager (Fuji, Nakanuma, Japan). For reasons of normalisation, membranes were boiled in water and rehybridised with a probe for $\beta$-actin. Quantified individual expression values were first normalised by corresponding $\beta$ actin values and then compared with each other.

\section{Determination of cell proliferation and cell number}

Cell proliferation was determined by the thymidine incorporation assay (O'Keefe et al, 1988). Cells were seeded in 96-well plates and were transiently transfected with a given plasmid construct (60 wells of a microtitre plate corresponded to one transfection experiment, wells of the margin were only filled with growth medium). For induction, doxycycline was added to every second well. Two days after transfection, wells were washed once with growth medium, and cells were incubated in growth medium containing ${ }^{3} \mathrm{H}$-thymidine $\left(2.5 \mu \mathrm{Ci} \mathrm{ml}{ }^{-1} ; 68.5 \mathrm{Ci} \mathrm{mmol}^{-1}\right)$ for $2 \mathrm{~h}$. After harvesting the cells with a cell harvester, tritium incorporation was measured in a scintillation counter. Ratios of each two neighbouring wells (induced versus non-induced) were determined and a mean value (induced versus non-induced) was calculated for each microtitre plate. At least three independent experiments (three microtitre plates) were performed for each combination of cell line and plasmid construct, and finally mean values and standard deviations were calculated from individual experiments.

Comparison of proliferation of stably transfected cell clones was performed in a similar way, only no transient transfection was needed, and cells were harvested 2 days after induction with doxycycline. Also here, one experiment corresponded to one microtiter plate and at least three independent experiments were performed for each cell line.

Cell numbers were determined 2 days after transient transfection either by direct cell counting in a Neubauer chamber or by the crystal violet assay described by Gillies et al (1986). In brief, cells grown in six-wells were fixed for $30 \mathrm{~min}$ with $1 \%$ glutaraldehyde and stained for another $30 \mathrm{~min}$ in a $0.01 \%$ crystal violet solution in PBS. Plates were washed in deionised water for $30 \mathrm{~min}$, and were then completely dried. Crystal violet absorbed by cell nuclei was solubilised with $0.2 \%$ Triton $\mathrm{X}-100$ in PBS. Aliquots were measured in an ELISA-Reader at $550 \mathrm{~nm}$.

\section{Statistical analysis}

For statistical analysis, the individual values (single wells) of an experiment were normalised by the mean value of the respective experiment. Thus, values of independent experiments could be combined in groups and resulted in an induced $(+)$ group and a not induced $(-)$ group. To demonstrate statistical significance of inhibition of cell proliferation or reduced cell numbers due to induction of antisense constructs, Student's $t$-test was applied (unpaired and heteroscedastic).

\section{RESULTS}

\section{Establishment of Tet-On melanoma cell lines}

As a prerequisite for applying the tetracycline-regulated gene expression system described by Gossen and Bujard (1992) for melanoma cells, we prepared suitable Tet-On cell lines by stable transfection of the pTet-On plasmid into the undifferentiated and amelanotic melanoma cell line Bro as well as into the differentiated melanoma cell line SK-Mel-13 characterised both by dendrite and melanin formation. After transfection, several geneticin-resistant cell clones were isolated, which were subsequently screened for their doxycycline inducibility using a luciferase reporter plasmid. One clone of each transfection was selected which showed the highest doxycycline inducibility: Bro-Tet-On and SKM13-Tet-On.

In order to optimise transient melanoma cell transfection, a series of different lipids and conditions were tested. The use of different lipids resulted in dramatic differences in transfection efficiency of more than 200-fold; responses of both melanoma cell lines to different lipids were in parallel (data not shown). Thus, optimisation of transfection conditions for a certain cell type seemed to be absolutely required. Luciferase activity obtained by the improved transfection protocol (see Materials and Methods) and after doxycycline induction was equivalent to $7 \times 10^{6}$ enzyme units per $10^{6}$ Bro-Tet-On cells, and to $3 \times 10^{6}$ units per $10^{6}$ SKM13-Tet-On cells, respectively, what was more than 1000 -fold over background (untransfected cells). The induction factors resulted from doxycycline treatment as compared to non-induced cell cultures were $22 \pm 6$ (Bro-Tet-On) and $28 \pm 9$ for SKM13Tet-On, respectively. 


\section{Construction of antisense plasmids}

For expression of antisense-RNA directed against the translation initiation factor eIF-4A1, three different cDNA fragments, from the cDNA 5 '-end, of the central portion and from the $3^{\prime}$-end, were subcloned in antisense orientation into a tetracycline responsive expression plasmid downstream of the tetracycline-inducible promoter. For answering the question whether a higher copy number may be critical for an antisense effect, the central-fragment was also subcloned in tandem in antisense orientation. As negative controls, the central-fragment was subcloned as one and as two tandem copies in sense orientation (Table 1).

For investigating the expression and inducibility of corresponding RNAs, cells were transiently transfected with the plasmid constructs, and doxycycline induced cells were compared 2 days later with non-induced cells, at the RNA level. As demonstrated in Figure 1, specific RNA expression was found after transient transfection for all plasmids constructed. After doxycycline induction, a strong increase of all plasmid-encoded RNAs was visible in both cell lines when compared to cultures grown without doxycycline. The steady state concentrations of endogeneous eIF-4A1 mRNA were difficult to quantify due to the high background of construct-specific RNA after transient transfection, but were not significantly reduced for any of the constructs, two days after transfection and induction (data not shown).

\section{Antiproliferative effects caused by antisense constructs against eIF-4A1, after transient transfection and induction of antisense constructs}

As translation efficiency may be a critical checkpoint for cell proliferation, we determined cell proliferation rates after transient transfection and compared cells induced with doxycycline versus cells grown without. As shown in Figure 2, thymidine incorporation rates in cells transiently transfected with three antisense constructs were significantly reduced after doxycycline induction. Relative proliferation rates for induced Bro-Tet-On cells as compared to non-induced cells were at $90.4 \pm 2.5 \%$ after transfection of antisense-2x-central, $92.6 \pm 3.8 \%$ for antisense-central, and $90.8 \pm 4.6 \%$ for antisense- $5^{\prime}$-end (Figure $2 \mathrm{~A}$ ). The antiproliferative antisense effects observed for SKM13-Tet-On after induction were largely in parallel: $89.8 \pm 4.3 \%$ for antisense- $2 x$-central, $90.6 \pm 7.1 \%$ for antisense-central, and $93.9 \pm 2.6 \%$ for antisense- $5^{\prime}$-end (Figure 2B). As each experiment consisted of 60 individually counted wells and was repeated at least three times, values were statistically significant (P-values see legend of Figure 2).

No antiproliferative effect, however, was seen for both of the sense controls (sense-central and sense-2x-central) as well as for a luciferase-encoding plasmid used as an additional control. Also, no antiproliferative effect was seen for the antisense construct directed against the $3^{\prime}$-end (antisense- $3^{\prime}$-end) for any of both cell lines. As can be concluded from the comparison of the effects caused by antisense-central versus antisense-2x-central, doubling of the copy number was not able to significantly increase the antiproliferative effect (Figure 2).

Also, cell numbers were determined after transient transfection of AS-2x-central as compared to sense-2x-central in SKM13-TetOn and Bro-Tet-On. Significantly reduced cell numbers were found 2 days after induction of antisense RNA, comparable to the results obtained by the tritium thymidine incorporation assay (Table 2 ).

\section{Reduced proliferation in stable transfected melanoma cell lines after induction of antisense constructs}

To investigate whether the antiproliferative effect is retained after stable transfection, when smaller amounts of antisense-RNA have to be expected than after transient transfection, we stably transfected the melanoma cell line Bro-Tet-On with antisense- $2 x$-central. In the following, five individual hygromycin-resistant cell clones were analysed. We first looked for eIF-4A1-specific RNA in the transfected cell clones, after doxycycline induction: No detectable levels of antisense RNA were found after Northern analysis, however, quantification of the endogeneous sense mRNA for eIF-4A1 $(1850 \mathrm{~N}$ and $1550 \mathrm{~N})$ revealed a decrease 2 days after doxycycline induction in all of the five clones, whereas the parent cell line, Bro-Tet-On, did not respond to doxycycline (Figures 3A and 4).

Proliferation assays revealed for three of the five clones significantly reduced proliferation rates after doxycycline induction as compared to non-induced cells, whereas, the parent cell line BroTet-On did not show a proliferation decrease (Figure $3 \mathrm{~B}$ ).

\section{DISCUSSION}

Gene expression in eucaryotes is regulated at several levels including the level of mRNA translation. In the last years, a series of reviews has been published on translational control giving a high impact on its role in cell growth and tumorigenesis (Clemens and Bommer, 1999; Jagus et al, 1999; Willis, 1999; Caraglia et al, 2000; Zimmer et $a l, 2000)$. Translational control no longer appears as a general and unselective control mechanism, but an increasing number of proteins were identified which are selectively regulated and which are involved in control of cell cycle and proliferation. Initiation of protein synthesis turned out as the rate-limiting step in translational control with particular attention being paid to expression and activation of eIF- $2 \alpha$ and eIF-4E, which are activated and inactivated by phosphorylation, respectively (Jagus et al, 1999; Zimmer et al, 2000).

A relation between translational control and malignant cell transformation became obvious, when elevated levels of eIF-4E as well as reduced levels of the eIF- $2 \alpha$ kinase, PKR, were detected in cancer cells (Kerekatte et al, 1995; Nathan et al, 1997; Jagus et $a l, 1999)$. Furthermore, overexpression of eIF-4E induced transformation (Rhoads, 1993), and its inhibition by antisense RNA decreased the malignancy of transformed cells (Graff et al, 1995). The oncogenic potential of eIF- $2 \alpha$ was demonstrated by inhibition of its phosphorylation (Jagus et al, 1999). These findings on eIF-4E, eIF- $2 \alpha$ and their kinases have resulted in the definition of a new group of translational oncogenes. Only limited data were available about the expression of translation factors in melanoma as well as about the role of eIF-4A1 in tumorigenesis. In a previous study, we reported consistent upregulation of eIF-4A1 mRNA in melanoma cell lines, as compared to normal human melanocytes, which led us suggest that eIF-4A1 may be related to melanoma cell transformation (Eberle et al, 1997).

Antisense techniques are powerful strategies to act against the malignant potential of genes upregulated in cancer. Having a pharmaceutical approach in mind, preferentially antisense oligonucleotides have been tested for their usefulness in cancer therapy. For an antisense-based, gene therapeutic approach, however, viral vectors and antisense RNA expression are needed. For melanoma, clinical studies using antisense oligonucleotides against the antiapoptotic $\mathrm{Bcl}-2$ are on the way aiming the sensitisation of tumour cells against chemotherapy (Jansen et al, 2000). Several other genes were targeted in melanoma cells by in vitro studies, as the anti-apoptotic factor survivin (Grossman et al, 1999), the transcription factor c-myc (Citro et al, 1998) and the growth factor pleiotrophin (Satyamoorthy et al, 2000).

In the present study, we investigated whether eIF-4A1 can be targeted in cultured melanoma cells by overexpression of antisense RNA using antisense plasmid constructs. In order to reach high comparability, we established the tetracycline-regulated expression system in human melanoma cell lines, which allowed the direct comparison between induced and non-induced cells; also relatively weak differences could be quantified this way. Significant antiproliferative effects were found after induction of three different eIF$4 \mathrm{~A} 1$ antisense constructs, both after transient and after stable transfection. The only limited antiproliferative effect which was obtained 
Table I Antisense and control plasmids used against elF-4A I

\begin{tabular}{lcccccr}
\hline pTRE constructs $^{\mathrm{a}}$ & $\mathbf{5}^{\prime} \mathbf{e n d}^{\mathrm{b}}$ & $\mathbf{3}^{\prime} \mathbf{e n d}^{\mathrm{b}}$ & Copies & Orientation & cDNA $^{\mathrm{c}}$ & $\mathbf{R N A}^{\mathrm{d}}$ \\
\hline AS-5'-end & 46 & 304 & $\mid$ & anti & 258 & 400 \\
AS-3'-end & $84 \mid$ & $|45|$ & $\mid$ & anti & 610 & 1000 \\
AS-central & 304 & 600 & $\mid$ & anti & 304 & 450 \\
AS-2x-central & 304 & 600 & 2 & anti/anti & 608 & 900 \\
Sense-central & 304 & 600 & $\mid$ & sense & 304 & 450 \\
Sense-2x-central & 304 & 600 & 2 & sense/sense & 608 & 900 \\
\hline
\end{tabular}

${ }^{a}$ Four antisense (AS) constructs of elF-4AI fragments and two sense controls were established in the expression plasmid PTRE. 'Positions of $5^{\prime}$ - and $3^{\prime}$-ends of the fragments, used, are given in respect to the ATG and in accordance to the published sequence of elF-4AI cDNA coding region (Kim et al, 1993) and extended 3' end (Eberle et al, 1997). 'Length of the subcloned cDNA fragments. 'Length of the resulting RNA as determined by Northern blotting.

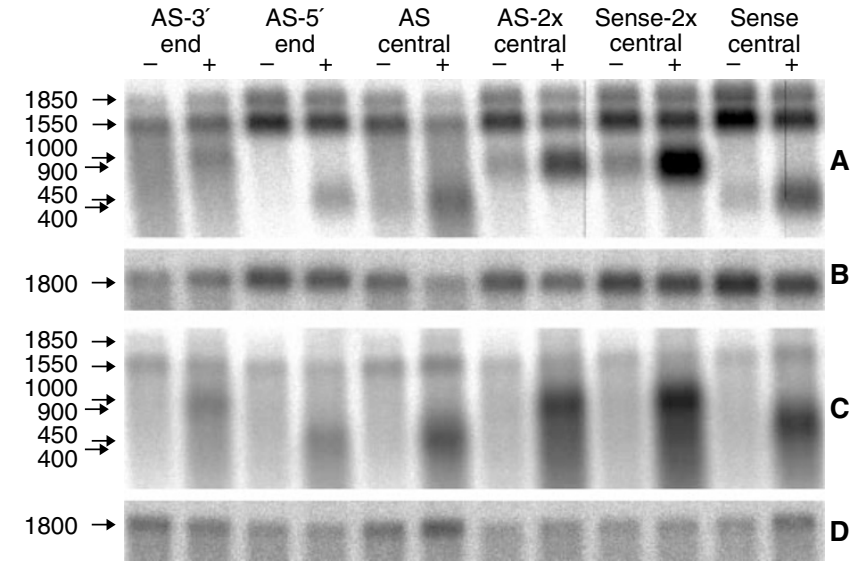

Figure I Expression of antisense RNA. Northern blots are shown of the cell lines SKMI3-Tet-On (A and $\mathbf{B})$ and of Bro-Tet-On (C and $\mathbf{D})$. Total RNA was extracted 2 days after transient transfection of six different antisense and sense constructs for translation initiation factor elF-4AI subcloned behind a tetracycline-inducible promoter (names of constructs are given in the top). Cell cultures grown with doxycycline $(+)$ were compared with cultures grown without doxycycline $(-)$. Northern blots were hybridised with CDNA probes specific for elF-4AI (A and $\mathbf{C})$ and for $\beta$ actin (B and $\mathbf{D}$ ), respectively. The position and length of the endogeneous mRNAs for elF-4AI (I850 N and I550 N), of $\beta$-actin (I800 N), and of the different plasmid-derived RNAs is indicated at the left margin.

in all transfection experiments (up to $10 \%$ reduction) has to be seen in relation to the relatively high expression of eIF-4Al mRNA in melanoma cells, comparable to the expression of major proteins as glycolytic enzymes and $\beta$-tubulin (Eberle et al, 1995a).

Due to the experience with antisense oligonucleotides, it is generally assumed that antisense can either result in reduction of the targeted mRNA due to specific ribonucleases or in direct obstruction of translation (Crooke, 1999). After stable transfection, we observed reduction of eIF-4A1 steady state RNA level, whereas this was not seen after transient transfection indicating that reduction of mRNA was not necessary in these experiments for obtaining the antiproliferative effect. Doubling of the copy number by using a tandem repeat of an antisense fragment did not further enhance the antisense effect, possibly indicating that a saturation point was already reached. Experience with antisense oligonucleotides had also shown that the effect of a given oligonucleotide is strongly dependent on the particular sequence targeted (Dean et $a l, 1994)$. This was also true in our approach, where we found comparable effects for a $5^{\prime}$ fragment and a central fragment whereas a $3^{\prime}$ fragment did not result in any proliferation effect. The data presented here demonstrate that human melanoma cells can be targeted by antisense constructs, even when the targeted mRNA is strongly expressed as in the case of eIF-4A1.
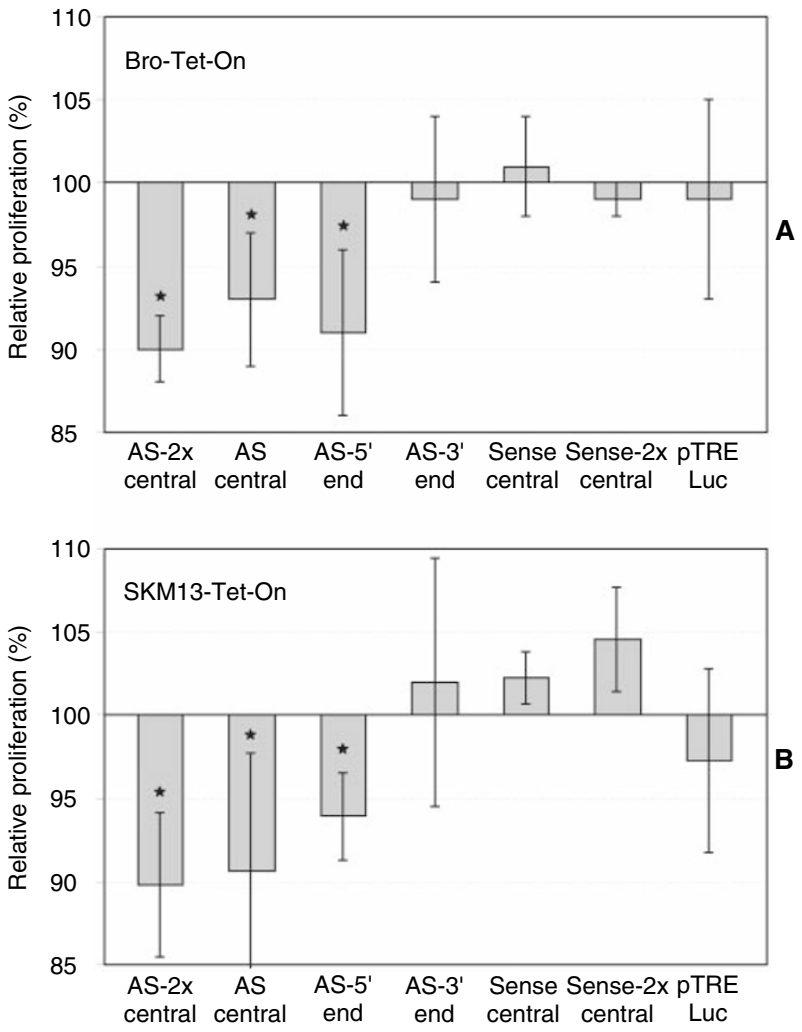

Figure 2 Reduced proliferation after transient transfection. Cell lines Bro-Tet-On (A) and SKMI 3-Tet-On (B) were transiently transfected with four antisense constructs (AS), two sense controls and the luciferase-encoding plasmid pTRE-Luc used as an additional control. Proliferation rates were determined in microtiter plates two days after transfection and induction with doxycycline. Relative proliferation rates were calculated as the ratio between cultures induced with doxycycline versus non-induced cultures (in \%), and bars represent deviations from 100\%. Each of the bars corresponds to mean values of at least three independent experiments of each 60 counted wells ( 180 wells). Significant reduction of proliferation is indicated by asterisks. According to Student's t-test, $P$-values for Bro-Tet-On were $<0.000$ I (AS-2x-central), $<0.005$ (AS-central), $<0.0002$ (AS-5'end); $P$-values for SKMI3-Tet-On were $<0.0001$ (AS-2x-central), $<0.000$ I (AS-central), $<0.02$ (AS-5'-end).

Due to a sequence comparison of translationally controlled mRNA species, it was predicted that many proliferation-related proteins will be regulated at the translational level (Kozak, 1991). The predicted secondary structures in their $5^{\prime}$ untranslated regions seem to be inhibitory for the ribosomal scanning process resulting in a dependence on the unwinding machinery (Sonenberg, 1996), which is based in particular on RNA helicase activity of eIF-4A1. 
Table 2 Reduced cell numbers after induction of antisense RNA

\begin{tabular}{lcccc}
\hline Cells $^{\mathrm{a}}$ & Plasmid constructs $^{\mathrm{a}}$ & $\mathbf{+}$ - $^{\mathrm{b}}$ & SD & t-test $^{\mathrm{c}}$ \\
\hline Bro-Tet-On & sense-2x-central & 1.00 & 0.04 & \\
Bro-Tet-On & AS-2x-central & 0.93 & 0.04 & $<0.003$ \\
SKMI3-Tet-On & sense-2x-central & 0.98 & 0.04 & \\
SKMI3-Tet-On & AS-2x-central & 0.93 & 0.03 & $<0.00$ I \\
\hline
\end{tabular}

${ }^{a}$ Two Tet-On melanoma cell lines were transiently transfected with the antisense construct AS-2x-central and with the sense control, respectively. ${ }^{b}$ Cell numbers were determined for doxycycline-induced cells $(+)$, by crystal violet assay, and were compared to non induced cells $(-)$, the ratio $(+/-)$ is given here. 'Statistical significance of reduced cell numbers after doxycycline induction in antisense-transfected cells was determined by unpaired Student's t-test.
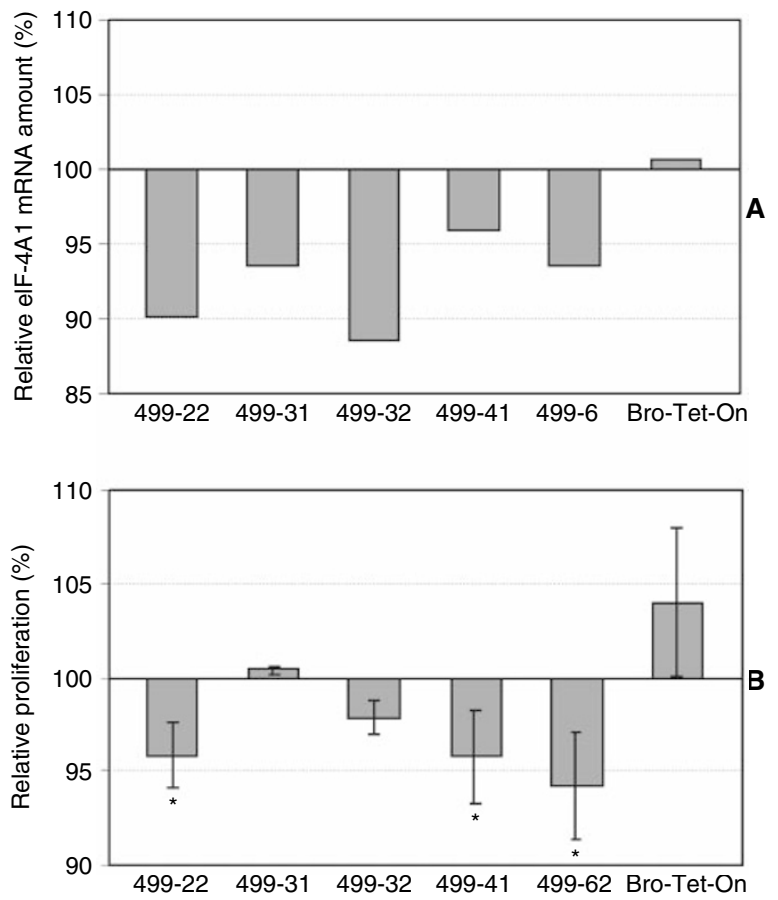

Figure 3 Reduced proliferation after induction of AS-2x-central in stably transfected cell clones. The cell line Bro-Tet-On was stably transfected with the antisense construct AS-2x-central. Five individual cell clones (499) as well as the parent cell line Bro-Tet-On were analysed 2 days after induction with doxycycline. (A) Amount of endogeneous mRNA for elF-4AI, as determined by Northern blotting, densitometry and normalisation with $\beta$-actin mRNA (median values of two independent experiments). (B) Relative proliferation rates were calculated as the ratio between cultures induced with doxycycline versus non-induced cultures (in \%), and the bars represent deviations from $100 \%$. Each of the bars corresponds to mean values of at least three independent experiments of each 60 counted wells (I 80 wells). Significant reduction of proliferation is indicated by asterisks. According to Student's $t$-test, $P$-values were $<0.03$ (499-22), $<0.02$ (499-4I), $<0.002$ (499-62).

\section{REFERENCES}

Bernstein J, Sella O, Le SY, Elroy-Stein O (1997) PDGF2/c-sis mRNA leader contains a differentiation-linked internal ribosomal entry site (D-IRES). $J$ Biol Chem 272: $9356-9362$

Birnboim HC, Doly J (1979) A rapid alkaline extraction procedure for screening recombinant plasmid DNA. Nucl. Acids Res 7: 1513-1523

Caraglia M, Budillon A, Vitale G, Lupoli G, Tagliaferri P, Abbruzzese A (2000) Modulation of molecular mechanisms involved in protein synthesis machinery as a new tool for the control of cell proliferation. Eur J Biochem 267: $3919-3936$

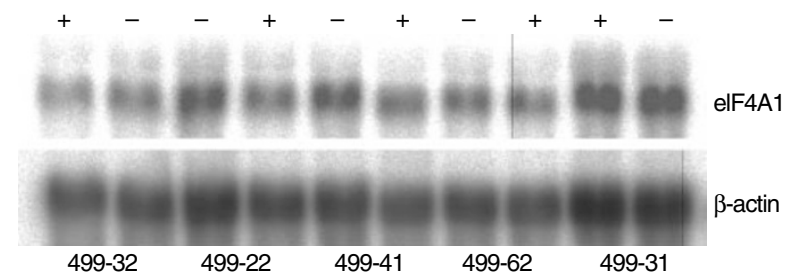

Figure 4 Reduced elF-4AI mRNA amounts after induction of AS-2xcentral in stably transfected cell clones. The Tet-On cell line Bro-Tet-On was stably transfected with the antisense construct AS-2x-central. Amounts of elF-4AI mRNA were determined by Northern blotting after induction $(+)$ and without induction $(-)$ with doxycycline in five individual cell clones (499-). Expression levels for $\beta$-actin were analysed in parallel and were used for normalisation.

There are many examples of translationally regulated growth factors and cytokines (Nielsen et al, 1995; Vagner et al, 1995; Bernstein et al, 1997). Furthermore, translational control has been shown for the cell cycle regulator cyclin D1 (Rosenwald et al, 1993), the transcription factor c-myc (Nanbru et al, 1997), several protein kinases (Marth et al, 1988; Yew et al, 1993) as well as for the key enzymes of polyamine synthesis which is closely linked to cell proliferation (Ruan et al, 1996). Therefore, the significance of translational control for cell proliferation became obvious. Furthermore, the oncogenic potential of several translationally regulated genes has been reported. In agreement, we found significant antiproliferative effects after induction of antisense RNA against eIF$4 \mathrm{~A} 1$, strongly suggesting that in human melanoma cells, eIF-4A plays at least an auxiliary role in regulation of cellular proliferation. This assumption is further promoted by the finding that only eIF$4 \mathrm{~A} 1$ but none of the other group 4 translation factors (eIF-4E, eIF$4 \mathrm{~B}$, eIF-4G, eIF-4A2) was significantly upregulated in melanoma cells as compared to normal melanocytes (Eberle et al, 1997).

In conclusion, our data underline the role of translation factors for cell proliferation and support the concept of translational oncogenes. Recent studies have focussed on the role of the factors eIF$4 \mathrm{E}$ and eIF- $2 \alpha$ in malignant cell transformation; no data were available on melanoma cells. Our data suggest that a concerted action of several translation factors, including eIF-4A1, may be decisive for the translational contribution to melanoma development. It is likely that future therapeutic strategies will simultaneously target several genes also including the translational level. Due to the rather limited growth effect obtained after stable transfection, antisense gene therapies exclusively against eIF-4A1 would be not sufficient in melanoma, however, they may be contributory and helpful in combination with other gene targets.

\section{ACKNOWLEDGEMENTS}

This study was supported by the Deutsche Forschungsgemeinschaft, grant $\mathrm{Eb}$ 148/1-2, /1-3.

Carey TE, Takahashi T, Resnick LA, Oettgen HF, Old LJ (1976) Cell surface antigens of human malignant melanoma: mixed hemadsorption assays for humoral immunity to cultured autologous melanoma cells. Proc Natl Acad Sci USA 73: $3278-3282$

Citro G, D’Agnano I, Leonetti C, Perini R, Bucci B, Zon G, Calabretta B, Zupi $\mathrm{G}$ (1998) c-myc antisense oligodeoxynucleotides enhance the efficacy of cisplatin in melanoma chemotherapy in vitro and in nude mice. Cancer Res 58: $283-289$ 
Clemens MJ, Bommer UA (1999) Translational control: the cancer connection. Int J Biochem Cell Biol 31: 1-23

Crooke ST (1999) Molecular mechanisms of action of antisense drugs. Biochim Biophys Acta 1489: 31-44

Dean NM, McKay R, Condon TP, Bennett CF (1994) Inhibition of protein kinase C-alpha expression in human A549 cells by antisense oligonucleotides inhibits induction of intercellular adhesion molecule 1 (ICAM-1) mRNA by phorbol esters. J Biol Chem 269: 16416-16424

De Wet JR, Wood KV, DeLuca M, Helinski DR, Subramani S (1987) Firefly luciferase gene: structure and expression in mammalian cells. Mol Cell Biol 7: $725-737$

Donze O, Jagus R, Koromilas AE, Hershey JW, Sonenberg N (1995) Abrogation of translation initiation factor eIF-2 phosphorylation causes malignant transformation of NIH 3T3 cells. EMBO J 14: $3828-3834$

Eberle J, Garbe C, Orfanos CE (1995a) Identification of genes specifically regulated in human melanoma cells. Arch Dermatol Res 287: 421-427

Eberle J, Garbe C, Wang N, Orfanos CE (1995b) Incomplete expression of the tyrosinase gene family (tyrosinase, TRP-1 and TRP-2) in human malignant melanoma cells in vitro. Pigment Cell Res 8: $307-313$

Eberle J, Krasagakis K, Orfanos CE (1997) Translation initiation factor eIF4A1 mRNA is consistently overexpressed in human melanoma cells in vitro. Int J Cancer 71: 396-401

Eberle J, Weitmann S, Thieck O, Pech H, Paul M, Orfanos CE (1999) Downregulation of endothelin $B$ receptor in human melanoma cell lines parallel to differentiation genes. J Invest Dermatol 112: 925-932

Kozak M (1991) An analysis of vertebrate mRNA sequences: intimations of translational control. J Cell Biol 115: 887-903

Gillies RJ, Didier N, Denton M (1986) Determination of cell number in monolayer cultures. Anal Biochem 159: 109-113

Gossen M, Bujard H (1992) Tight control of gene expression in mammalian cells by tetracycline-responsive promoters. Proc Natl Acad Sci USA 89: 5547-5551

Graff JR, Boghaert ER, De Benedetti A, Tudor DL, Zimmer CC, Chan SK, Zimmer SG (1995) Reduction of translation initiation factor 4E decreases the malignancy of ras-transformed cloned rat embryo fibroblasts. Int Cancer 60: $255-263$

Grossman D, McNiff JM, Li F, Altieri DC (1999) Expression and targeting of the apoptosis inhibitor, survivin, in human melanoma. J Invest Dermatol 113: $1076-1081$

Jagus R, Joshi B, Barber GN (1999) PKR, apoptosis and cancer. Int J Biochem Cell Biol 31: 123-138

Jansen B, Wacheck V, Heere-Ress E, Schlagbauer-Wadl H, Hoeller C, Lucas T, Hoermann M, Hollenstein U, Wolff K, Pehamberger H (2000) Chemosensitisation of malignant melanoma by BCL2 antisense therapy. Lancet 356: $1728-1733$

Kerekatte V, Smiley K, Hu B, Smith A, Gelder F, De Benedetti A (1995) The proto-oncogene/translation factor eIF4E: a survey of its expression in breast carcinomas. Int J Cancer 64: 27-31

Kim NS, Kato T, Abe N, Kato S (1993) Nucleotide sequence of human cDNA encoding eukaryotic initiation factor 4AI. Nucl Acids Res 21: 2012

Lazaris-Karatzas A, Montine KS, Sonenberg N (1990) Malignant transformation by a eukaryotic initiation factor subunit that binds to mRNA $5^{\prime}$ cap. Nature 345: $544-547$
Lockshin A, Giovanella BC, De Ipolyi PD, Williams Jr LJ, Mendoza JT, Yim SO, Stehlin JSJ (1985) Exceptional lethality for nude mice of cells derived from a primary human melanoma. Cancer Res 45: 345-350

MacDonald RJ, Swift GH, Przybyla AE, Chirgwin JM (1987) Isolation of RNA using guanidinium salts. Methods Enzymol 152: 219-227

Marth JD, Overell RW, Meier KE, Krebs EG, Perlmutter RM (1988) Translational activation of the lck proto-oncogene. Nature 332: 171-173

Nanbru C, Lafon I, Audigier S, Gensac MC, Vagner S, Huez G, Prats AC (1997) Alternative translation of the proto-oncogene c-myc by an internal ribosome entry site. J Biol Chem 272: 32061 -32066

Nathan CA, Liu L, Li BD, Abreo FW, Nandy I, De Benedetti A (1997) Detection of the proto-oncogene eIF4E in surgical margins may predict recurrence in head and neck cancer. Oncogene 15: 579-584

Nielsen FC, Ostergaard L, Nielsen J, Christiansen J (1995) Growth-dependent translation of IGF-II mRNA by a rapamycin-sensitive pathway. Nature 377: $358-362$

O'Keefe EJ, Chiu ML, Payne Jr RE (1988) Stimulation of growth of keratinocytes by basic fibroblast growth factor. J Invest Dermatol 90: 767-769

Ray BK, Lawson TG, Kramer JC, Cladaras MH, Grifo JA, Abramson RD, Merrick WC, Thach RE (1985) ATP-dependent unwinding of messenger RNA structure by eukaryotic initiation factors. J Biol Chem 260: $7651-$ 7658

Rhoads RE (1993) Regulation of eukaryotic protein synthesis by initiation factors. J Biol Chem 268: 3017-3020

Rosenwald IB, Lazaris-Karatzas A, Sonenberg N, Schmidt EV (1993) Elevated levels of cyclin D1 protein in response to increased expression of eukaryotic initiation factor 4E. Mol Cell Biol 13: $7358-7363$

Ruan H, Shantz LM, Pegg AE, Morris DR (1996) The upstream open reading frame of the mRNA encoding S-adenosylmethionine decarboxylase is a polyamine-responsive translational control element. J Biol Chem 271: $29576-29582$

Satyamoorthy K, Oka M, Herlyn M (2000) An antisense strategy for inhibition of human melanoma growth targets the growth factor pleiotrophin. Pigment Cell Res 13:(Suppl 8): $87-93$

Sonenberg N (1996) mRNA 5' cap-binding Protein eIF-4E and control of cell growth. In Translational Control, Hershey JWB, Mathews MB, Sonenberg N (eds) pp 245-269. Cold Spring Harbor: Cold Spring Harbor Laboratory Press

Thomas PS (1980) Hybridization of denatured RNA and small DNA fragments transferred to nitrocellulose. Proc Natl Acad Sci USA 77: 5201 - 5205

Vagner S, Gensac MC, Maret A, Bayard F, Amalric F, Prats H, Prats AC (1995) Alternative translation of human fibroblast growth factor 2 mRNA occurs by internal entry of ribosomes. Mol Cell Biol 15: 35-44

Willis A (1999) Translational control of growth factor and proto-oncogene expression. Int J Biochem Cell Biol 31: 73-86

Yew N, Strobel M, Van de Woude GF (1993) Mos and the cell cycle: the molecular basis of the transformed phenotype. Curr Opin Genet Dev 3: $19-25$

Zimmer SG, DeBenedetti A, Graff JR (2000) Translational control of malignancy: the mRNA cap-binding protein, eIF-4E, as a central regulator of tumor formation, growth, invasion and metastasis. Anticancer Res 20: $1343-1351$ 